\title{
Forearm lump and osteoporosis
}

\author{
Mara CARSOTE ${ }^{1,2}$, Simona Elena ALBU ${ }^{1,3}$, \\ Florica SANDRU ${ }^{1,4}$, Mihai Cristian DUMITRASCU ${ }^{1,3}$, Anda DUMITRASCU ${ }^{2}$, Ana VALEA ${ }^{5,6}$ \\ 1 "Carol Davila" University of Medicine and Pharmacy, Bucharest, Romania \\ 2 "C.I. Parhon" National Institute of Endocrinology, Bucharest, Romania \\ ${ }^{3}$ Emergency University Hospital, Bucharest, Romania \\ ${ }^{4}$ Elias Emergency University Hospital, Bucharest, Romania \\ ${ }^{5}$ Clinical County Hospital, Cluj-Napoca, Romania \\ 6 "Iuliu Hatieganu" University of Medicine and Pharmacy, Cluj-Napoca, Romania
}

\begin{abstract}
We introduce a case of a menopausal woman newly diagnosed with primary osteoporosis who has been detected with a forearm lump. A 57-year old female is confirmed with osteoporosis at DXA. The patient developed within 10 days a painful lump with local redness at dorso-medial part of left forearm. Apparently no local trauma was identified. Neither had she a general infection or any other condition in the mean time. The ultrasound identified a hypoechoic area of 4 by 1.3 by $4 \mathrm{~cm}$, with positive Doppler signal. A local infection was considered and she was offered antibiotics for 10 days. However, since the patient also accused bone pain, she was re-referred for an endocrine assessment. The hormonal panel was consistent with the first assays. Also a mild inflammatory syndrome was detected based on erythrocytes sedimentation rate of $31 \mathrm{~mm} / 1$-hour (normal: $<25 \mathrm{~mm} / 1-\mathrm{h}$ ) and C reactive protein of $1.4 \mathrm{mg} / \mathrm{dl}$ (normal: $<1 \mathrm{ng} / \mathrm{ml}$ ). An X-Ray of the region was done and showed no anomaly. The bone whole body scintigram was negative at forearm but a fracture rib at the level of 9th left rib was identified and considered osteoporotic. A computed tomography showed the subcutaneous localisation of the lump with small calcifications and no bone involvement. Paget's disease of the bone was excluded based on normal bone turnover markers and negative bone scintigram. The proximity with a bone disease diagnosis needs to differentiate a subcutaneous lesion from a potential bone deformity caused by a metabolic bone condition.
\end{abstract}

Keywords: lump, forearm, osteoporosis, bone

\author{
Abbreviations \\ $\mathrm{BMD}=$ bone mineral density \\ DXA = Dual-Energy X-Ray Absorptiometry \\ $\mathrm{PET} / \mathrm{CT}=$ positron emission tomography/computed tomography \\ $\mathrm{SD}=$ standard deviation
}

\section{INTRODUCTION}

Osteoporosis is a complex dual disease of the bone $(1,2)$. Except for kyphosis and the fragility fractures themselves there is not a specific skin sign associated with this condition, neither a bone deformity except for potential spine anomalies due to vertebral fractures $(3,4)$. However, bone metabolic conditions like Paget's disease need to be differentiated from osteoporosis and bone deformities might be found in this particular situation $(5,6)$. 


\section{AIM}

Our purpose is to introduce a case of a menopausal woman newly diagnosed with primary osteoporosis who has been detected with a forearm lump of apparently unknown origin.

\section{MATERIAL AND METHOD}

This is a case report. Clinical, endocrine and imaging data are introduced.

\section{CASE REPORT}

This is a 57 year old female referred after general practitioner and gynaecological exam suspected osteoporosis. One year ago she suffered a unilateral low-trauma should fracture. She had spontaneous menopause at age of 50 years with no hormonal replacement therapy. The clinical exam was within normal limits for age at first evaluation. Blood tests revealed normal biochemistry parameters like ionic calcium of $4 \mathrm{mg} / \mathrm{dl}$ (normal: 3.9-4.9 mg/dl), and bone turnover markers of formation as osteocalcin of $19 \mathrm{ng} / \mathrm{ml}$ (normal: 15-46 $\mathrm{ng} / \mathrm{ml}$ ), and alkaline phosphatase of $80 \mathrm{U} / \mathrm{l}$ (normal: 38-105 $\mathrm{U} / \mathrm{I})$, but also a mild suppression of blood bone resorption maker CrossLaps of 0.146 $\mathrm{ng} / \mathrm{ml}$ (normal: 0.33-0.782 ng/ml). She had normal thyroid and adrenal function. No vitamin D deficiency was identified (she had a 25-hydroxyvitamin D of $30 \mathrm{ng} / \mathrm{ml}$ and parathormone of $32 \mathrm{pg} /$ $\mathrm{ml}$, normal levels between 15 and $65 \mathrm{pg} / \mathrm{ml}$ ).

Central DXA (Dual-Energy X-Ray Absorptiometry) showed a bone mineral density (BMD) at the lumbar spine of $0.743 \mathrm{~g} / \mathrm{sqcm}$, T-score of $-3.6 \mathrm{SD}$ (standard deviation), a Z-score of -2.5 SD, femoral

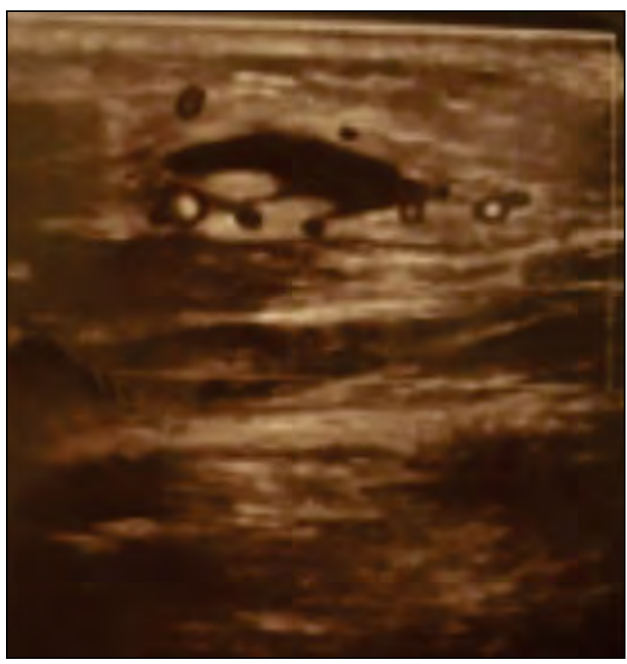

FIGURE 1. Ultrasound of the forearm at the level of lump showed hypoechoic area of 4 by 1.3 by 4 $\mathrm{cm}$, with positive Doppler signa neck BMD of $0.677 \mathrm{~g} / \mathrm{sqcm}$, T-score of $-2.6 \mathrm{SD}$, Z-score of -1.4 SD, total hip BMD of $0.67 \mathrm{~g} / \mathrm{sqcm}$, T-score of - 2.7 SD, Z-score of -1.8 SD, left (non-dominant arm) third distal radius BMD of $0.592 \mathrm{~g} / \mathrm{sqcm}$, T-score of -1.7 SD, Z-score of -1.2 SD. These data are consistent with the diagnosis of osteoporosis which was already clinically suspected based on previous fragility fracture. The screening profile X-Ray of the spine was negative for others fractures.

After the diagnosis of primary complicated osteoporosis was established specific medication was recommended with oral bisphosphonates (weekly alendronate) and supplements with vitamin $D$ and calcium. Soon the patient developed (within 10 days) at the level of left forearm a painful lump with local redness. Apparently no local trauma was identified by the patient before or during the lump growth. Neither had she had a general infection or any other condition in the mean time. The lesion had $3 \mathrm{~cm}$ (centimetre) diameter and it was located at the level of third dorso-medial part of the forearm. The local ultrasound identified a hypoechoic area of 4 by 1.3 by 4 $\mathrm{cm}$, with positive Doppler signal (Figure 1). A local infection was considered and she was offered antibiotics for 10 days.

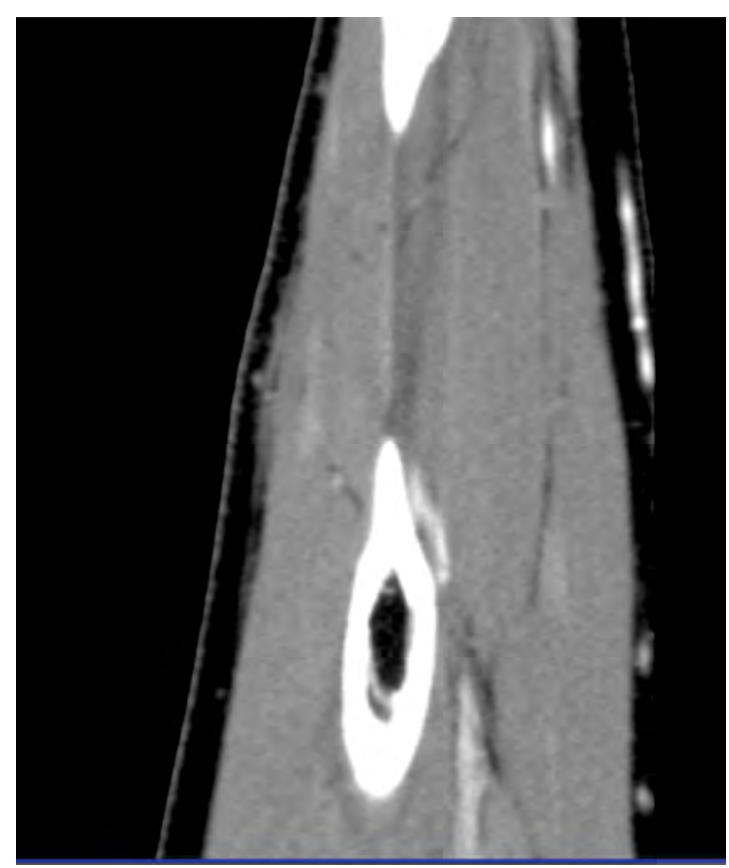

FIGURE 2. Computed tomography of the forearm at the level of lump confirmed no bone involvement

However, since the patient also accused bone pain, she was re-referred for an endocrine assessment. The hormonal panel was consistent with the first assays. Also a mild inflammatory syndrome was detected based on erythrocytes sedimentation rate of $31 \mathrm{~mm} / 1$-hour (normal less 
than $25 \mathrm{~mm} / 1-\mathrm{h}$ ) and C reactive protein of $1.4 \mathrm{mg} /$ $\mathrm{dL}$ (normal: 0-1 ng/ml). An X-Ray of the region was done and showed no anomaly. The bone whole body scintigram was negative at the level of the lump region except for a newly diagnosed fracture rib at the level of $9^{\text {th }}$ left rib which was considered also osteoporotic. A computed tomography showed the subcutaneous localisation of the lump with small calcifications and no bone involvement (Figure 2). Paget's disease of the bone was excluded and the diagnosis of menopausal osteoporosis was considered accidental. No change of prior recommendations regarding osteoporosis was done. Further periodic assessment is necessary.

\section{DISCUSSION}

Paget's disease of the bone has focal, single or multiple lesions with a relative slow progression affecting bone, joints and vascular areas (7). It has a relative high frequency in some populations but less than primary osteoporosis (7). Bone deformities as it might have been in this case are identified especially in pressure areas $(8,9,10)$. Serum total alkaline phosphatase remains the first line of assays even less than on fifths of cases had normal values $(5,10,11)$. In this case the bone turnover were within normal limits except for a small decrease of CrossLaps. Generally the bone turnover markers are considered with a high inter- and intra- individual variability $(12,13)$. The derivates from collagen are most useful in daily practice $(12,13,14)$. A recent fracture increases the bone markers for a while and they are not useful for establishing the diagnosis of osteoporosis (12). In Paget's disease or multiple myeloma the markers may reach to extremely high values $(10,12)$. Under biphosphonates the markers get low opposite to teriparatide therapy as an osteoanabolic option $(13,14,15)$. In this case we do not currently consider clinically relevant the value of CrossLaps.

Radionuclide bone scans are useful for positive diagnosis and for differential diagnosis as seen here regarding bone metabolic conditions $(5,10)$. Even a prior undetected fracture was identified at the rib the region with deformation was not active. Yet, there are authors who do not consider that the use of bone scintigraphy is as relevant in order to change the evaluation on patients with limb pain which is suspected to be connected with a musculoskeletal condition (18).

Local pain may be the first sign that allows the condition's detection based on clinical approach $(5,10)$. Another interesting differential diagnosis of the forearm lump might be a muscle metastasis $(19,20)$. There are only a few reports in the literature $(19,20)$. Direct muscle invasion from a cancer is atypical $(19,20)$. A case of a women with previous breast cancer identified a biceps metastasis which was treated with local radiotherapy (19). Another series of 205 patients with oesophageal cancer revealed 4 subjects with skeletal muscle metastasis based on PET/CT (positron emission tomography/computed tomography) scan (20). Fortunately this was not the case here even it was taken into consideration at the begging of re-assessment as a differential diagnosis.

\section{CONCLUSION}

The proximity with a bone disease diagnosis needs to differentiate a subcutaneous lesion from a potential bone deformity caused by a metabolic bone condition.

Conflict of interest: none declared Financial support: none declared

\section{REFERENCES}

1. Kanis JA, Cooper C, Rizzoli R, Reginster JY; Scientific Advisory Board of the European Society for Clinical and Economic Aspects of Osteoporosis (ESCEO) and the Committees of Scientific Advisors and National Societies of the International Osteoporosis Foundation (IOF). European guidance for the diagnosis and management of osteoporosis in postmenopausal women. Osteoporos Int. 2019 Jan; 30(1):3-44.

2. Kanis JA, Cooper C, Rizzoli R, Reginster JY; Scientific Advisory Board of the European Society for Clinical and Economic Aspects of Osteoporosis and Osteoarthritis
(ESCEO) and the Committees of Scientific Advisors and National Societies of the International Osteoporosis Foundation (IOF). Executive summary of European guidance for the diagnosis and management of osteoporosis in postmenopausal women. Aging Clin Exp Res. 2019 Jan;31(1):15-17.

3. Poiana C, Radoi V, Carsote M, Bilezekian J. New Clues that May Link Osteoporosis to the Circulating Lipid Profile. Bone Research 2013; 1(3):260-266.

4. Radu L, Carsote M, GheorghisanGalateanu AA, Preda SA, Calborean V, Stanescu R, Gheorman V, Albulescu DM.
Blood Parathyrin and Mineral Metabolism Dynamics. A clinical analyze. Rev.Chim. (Bucharest). 2018;69(10):2754-2758.

5. Muschitz C, Feichtinger X, Haschka J, Kocijan R. Diagnosis and treatment of Paget's disease of bone: A clinical practice guideline. Wien Med Wochenschr. 2017 Feb; 167(1-2):18-24.

6. Ghemigian A, Carsote M, Cocolos A, Dumitru N, Petrova E, Valea A, Muntean R, Goldstein A. Paget's disease of the bone (early diagnosis): How far is far away? Journal of Medical Practice. 2018; 13;2(57): 117-121. 
7. Appelman-Dijkstra NM, Papapoulos SE. Paget's disease of bone. Best Pract Res Clin Endocrinol Metab. 2018 Oct; 32(5):657-668.

8. Williams AE, O'Neill TW, Mercer S, Toro B, Nester CJ. Foot pathology in patients with Paget's disease of bone. J Am Podiatr Med Assoc. 2006 May-Jun;96(3):226-31.

9. Hsu E. Paget's disease of bone: Updates for clinicians. Curr Opin Endocrinol Diabetes Obes. 2019 Dec;26(6):329-334.

10. Ralston SH, Corral-Gudino L, Cooper C, Francis RM, Fraser WD, Gennari L, Guañabens N, Javaid MK, Layfield R, O'Neill TW, Russell RGG, Stone MD, Simpson K, Wilkinson D, Wills R, Zillikens MC, Tuck SP. Diagnosis and Management of Paget's Disease of Bone in Adults: A Clinical Guideline. J Bone Miner Res. 2019 Apr; 34(4):579-604.

11. Poiana C, Carsote M, Hortopan D, Coculescu M. Skull monoostotic Paget's disease of the bone-Case report and review of the literature, Acta Endocrinologica, 2007; III(3):333-344.
12. Eastell R, Szulc P. Use of bone turnover markers in postmenopausal osteoporosis. Lancet Diabetes Endocrinol. 2017 Nov; 5(11):908-923.

13. Bechir ES, Carsote M, Tuculina MJ, Bataiosu M, Dascalu IT, Raescu M, Rica R, Daguci C, Daguci L, Predescu A, Andrei OC, Mercut R, Cumpata CN. Biochemical Analysis of Mineral Metabolism and Central Bone Mineral Density in 157 Adult Women. Rev.Chim. (Bucharest). 2018; 69(12):3565-3568.

14. Carsote M, Preda SA, Mitroi M, Camen A, Radu L. Serum Osteocalcin, P1NP, Alkaline Phosphase, and CrossLaps in Humans: the relationship with body mass index. Rev. Chim. (Bucharest). 2019;70(5):1615-1618.

15. Radu L, Carsote M, Predescu AM, Cojan TS, Socea B, Baleanu VD, Popescu M, Ionovici N, Albulescu DM. Biochemical Parameters in Patients Using Teriparatide. Rev.Chim. (Bucharest). 2018; 69(12):3483-3485.

16. Tuculina MJ, Carsote M, Bataiosu M, Raescu M, Voinea-Georgescu R, Cumpata
$\mathrm{CN}$. Clinical Data on transitory teriparatiderelated hypercalcemia in daily practice treatment for severe menopausal osteoporosis. Revista de Chimie. 2019:70(9).3176-3179.

17. Carsote M, Ghemigian A, Radu O, Valea A. Teriparatide as option for severe osteoporosis. Journal of Medical Practice. 2016; 4(47)-11:324-330.

18. Ferrari R. Clinical utility of bone scintigraphy in patients with limb pain of suspected musculoskeletal origin. Eur J Rheumatol. 2015 Mar;2(1):16-19.

19. Almusarhed M, Eldeeb H. Solitary biceps muscle metastasis from breast cancer. BMJ Case Rep. 2017 Aug 20; 2017. pii: bcr-2017-220597.

20. Cincibuch J, Mysliveček M, Melichar B, Neoral C, Metelková I, Zezulová M, Procházková-Študentová $\mathrm{H}$, Flodr $\mathrm{P}$, Zlevorová M, Aujeský R, Cwiertka K. Metastases of esophageal carcinoma to skeletal muscle: single center experience. World J Gastroenterol. 2012 Sep 21; 18(35):4962-6. 